\author{
UnB - UNIVERSIDADE DE BRASÍLIA \\ CET - CENTRO DE EXCELÊNCIA EM TURISMO \\ COORDENAÇÃO DE PÓS-GRADUAÇÃO GESTÃO DA HOSPITALIDADE
}

\title{
INTERCÂMBIO DE ESTUDANTES BRASILIENSES PARA IRLANDA
}

\author{
Alice Rodrigues Madruga
}

Orientador drs. Philippus Johannes Heijblom

Monografia apresentada ao Centro de

Excelência em Turismo da

Universidade de Brasília como requisito parcial para a obtenção do certificado de Especialista em Gestão da Hospitalidade. 
UNIVERSIDADE DE BRASÍLIA

Centro de Excelência em Turismo

Curso de Especialização em Gestão da Hospitalidade

\section{INTERCÂMBIO DE ESTUDANTES BRASILEIROS PARA IRLANDA}

Alice Rodrigues Madruga

Banca Examinadora

drs. Philippus Johannes Heijblom

Orientador

Brasília, 30 de janeiro de 2004. 
Alice Rodrigues Madruga

\title{
INTERCÂMBIO DE ESTUDANTES BRASILIENSES PARA IRLANDA
}

\author{
Comissão Avaliadora
}

drs. Philippus Johannes Heijblom

Professor(a)

Professor(a)

Brasília, DF, 30 de janeiro de 2004. 


\section{Resumo}

A intenção desta monografia é avaliar o "Programa de Intercâmbio na Irlanda para aprendizagem da língua inglesa", analisando as características do país e do programa de intercâmbio, examinar se a Irlanda dispõe de potencial para competir com os principais países mais procurados no mercado de intercâmbio. Para isso, foi feita uma pesquisa literária apresentando os pontos fortes que a Irlanda possui para se destacar no mercado de intercâmbio. Também foi feita uma pesquisa com os estudantes brasilienses de algumas principais Instituições de ensino da língua inglesa, para obter informações do que influência os estudantes diante da escolha do país para destino do intercâmbio.

Chegou-se à conclusão que a Irlanda têm potencial para competir no mercado de intercâmbio, porém, o país terá que investir mais na divulgação do país.

Palavras chave: Intercâmbio, Irlanda, Potencial, Estudantes, Instituições 
The subject of this study is to evaluate the "Program of Interchange in Ireland to learn English", analyzing the features of the country and the program of interchange, search if the country has potential to compete with the main countries competing in the market of interchange. A study of Literature was realized about the best points that Ireland has to compete in the market of interchange. Another survey was realized with the students of the main Institutions that teach the English language, with the aim to get information of what influences the students to choose the country for the interchange.

The result of this research is that Ireland has potential to compete in the market of interchange of brazilian students in Ireland, but is very little chosen, however, the country will have to invest more in the advertising of its potential.

Key-words: Interchange, Ireland, Potential, Students, Institutions 


\section{Sumário}

1. Lista de Ilustrações

2. Lista de Abreviaturas $\ldots$

3. Introdução

4. Objetivos do estudo

5. Metodologia

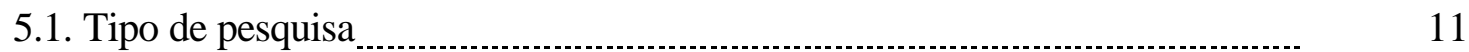

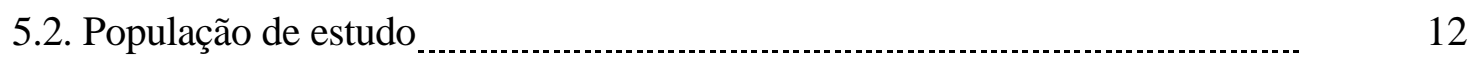

5.3. Caracterização da população

5.3.1. Estudantes das Instituições da Língua Inglesa ..................................... 13

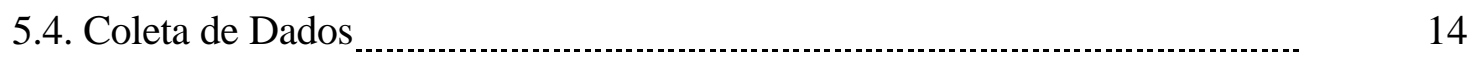

5.4.1. Questionário para estudantes de Inst. de Ensino da Língua Inglesa.. $\quad 14$

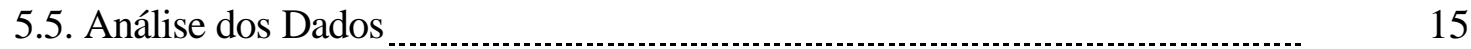

6. Intercâmbio

6.1. Antecedentes do Programa

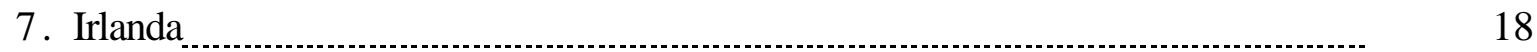

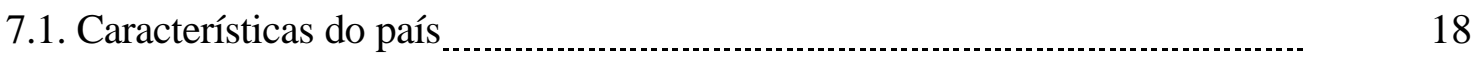

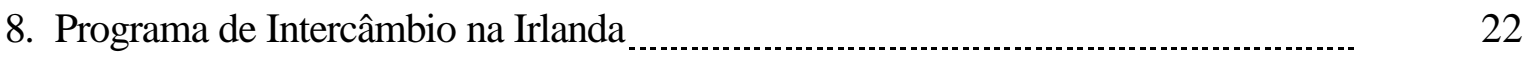

8.1. Caracterização do Programa ..................................................................

8.2. Histórico dos Parceiros no Mercado de Intercâmbio para Irlanda ................... 23

8.2.1 Conselho para Escolas da Língua Inglesa (ACELS) _.......................... 23

8.2.1 MEI RELSA Ireland - Associação irlandesa fornecedora do EFL ........... 24

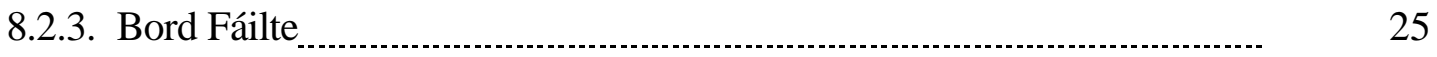

8.3. Potência do EFL no Mercado de Intercâmbio ...............................................

8.3.1. EFL no Mercado de Intercâmbio _.................................................... 27

8.3.2. Processo utilizado pelos estudantes que escolhem como destino o EFL. 27

8.3.3. Origem dos principais estudantes que escolhem como destino o EFL. 28

9. Países competidores no Mercado de Intercâmbio _................................................. 29 
9.1. Mercado Competidor da Inglaterra

9.1.1. Organização da Indústria

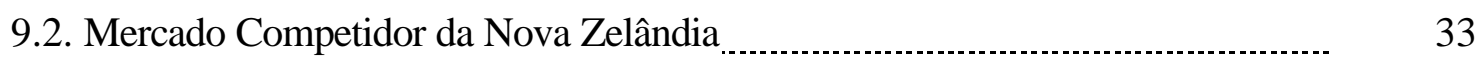

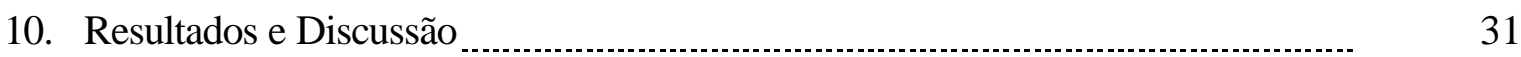

11. Conclusão

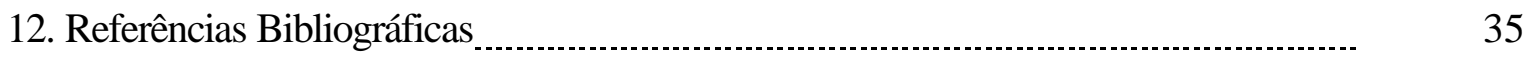

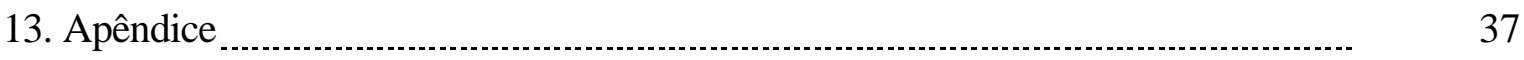




\section{Lista de Ilustrações}

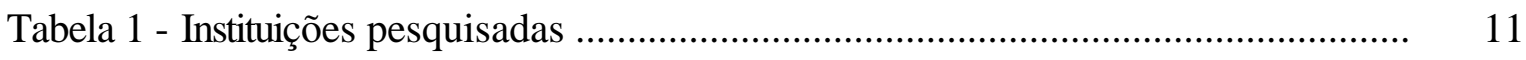

Figura 1 - Rio Liffey na cidade de Dublin - Irlanda................................................... 18

Figura 2 - Castelo de Mahalide na cidade Howth - Irlanda....................................... 19

Figura 3 - Mapa da Irlanda, Fonte: Bord Fáilte - Irish Tourist Board......................... 21 


\section{Lista de Abreviaturas}

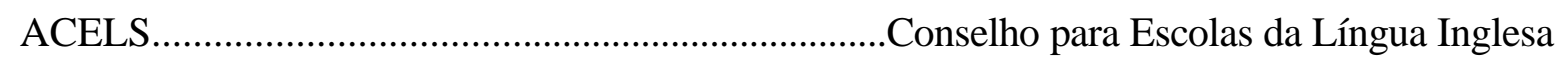
ARELS................................................Associação reconhecedora das escolas da língua inglesa BASELT ...................................... Associação Britânica Estadual de Ensino da Língua Inglesa Bord Fáilte..........................................................Departamento governamental responsável pelo marketing e divulgação da Irlanda como destino pelos estrangeiros para aprendizagem da língua inglesa.

EFL .Inglês na Irlanda para Estrangeiros MEI. ..Marketing do Inglês na Irlanda

MEI RELSA Ireland. Associação irlandesa fornecedora do $E F L$

RELSA. .Associação das Escolhas da Língua Inglesa 


\section{Introdução.}

Com a globalização e a crescente interação entre diferentes nações e culturas, as pessoas estão sentindo cada vez mais a necessidade de aprender uma segunda língua, destacando o idioma inglês por ser uma das línguas mais falada mundialmente, através de transmissores de comunicação; televisão, rádio, internet, etc.

Segundo Heliana Álvares, no mundo globalizado, a necessidade de comunicação vem obrigando os profissionais, principalmente os executivos, a dominar outro idioma. Cada vez mais as pessoas investem no aprendizado de uma outra língua, como forma de se garantir em um mercado altamente competitivo e sem fronteiras. Até hoje o inglês desponta como primeiro no ranking, seguido do espanhol, que vem se firmando como segunda língua mais procurada pelos brasileiros devido à consolidação do Mercosul. No Brasil, principalmente nos grandes centros, onde estão sediadas as grandes empresas e as representantes multinacionais, expressar-se em outro idioma já faz parte da bagagem de conhecimentos de altos executivos, ganhando terreno rapidamente para representantes de todas as áreas das empresas e todos os segmentos do mercado. ${ }^{1}$

$\mathrm{Na}$ busca para a aprendizagem da língua inglesa a maioria dos brasilienses escolhe como primeira opção um curso de língua em sua cidade; o mais próximo de sua residência, o tradicional ou onde seus amigos estudam, mais caro ou mais barato, entrem outras opções que não serão abordadas nesta pesquisa. Como segunda opção, escolhem um curso de línguas no exterior. Geralmente os cursos de inglês oferecem opções de aperfeiçoamento da língua mediante uma estadia por um período num país de língua inglesa, o tal chamado INTERCÂMBIO, durante o qual o estudante vive 24 horas por dia num ambiente aonde somente se fala inglês e que resulta geralmente num grande desenvolvimento da sua capacidade desta língua estrangeira.

\footnotetext{
${ }^{1}$ http://www.gestaoerh.com.br/visitante/artigos/cap_gp07.php
} 
Estudar no exterior é uma experiência cultural extraordinária e única que deixa recordações maravilhosas para o resta da vida. A permanência em um país estrangeiro lhe dá a oportunidade de conhecer outro povo, de aprender um novo idioma, de se tornar mais independente. Enfim, uma longa lista de vantagens. Não importa a idade. É sempre tempo de começar. O aprendizado não tem fim.

(Mac-Dowell,1998,pág.3)

Conforme publicado na pesquisa da Enterprise Ireland 2001, os países de língua inglesa mais procurados para intercâmbio são os Estados Unidos, Inglaterra, Austrália e Nova Zelândia. Pouco conhecido e divulgado é a opção da Irlanda como destino para intercâmbio.

O presente estudo, portanto, visa a pesquisa do país; Irlanda, como opção para intercâmbio dos estudantes brasilienses. 


\section{Objetivos do estudo.}

Levantamento quanto à motivação dos estudantes brasilienses para viagem de intercâmbio para aprendizagem da língua inglesa na Irlanda. Serão apresentados dados gerais sobre o país e especialmente as condições de intercâmbio para aprendizagem da língua inglesa. 


\section{Metodologia.}

Será realizada uma pesquisa de literatura sobre intercâmbio em geral, o sistema de aprendizagem da língua inglesa na Irlanda, um comparativo com outros países receptores de estudantes brasileiros para intercâmbio, e, ainda uma pesquisa quantitativa com estudantes matriculados em cursos de inglês no Distrito Federal.

\subsection{Tipo de pesquisa.}

O presente trabalho, utilizará a abordagem de estudo de caso, na medida em que se fizer necessário:

$\sqrt{ }$ enfatizar a "interpretação em contexto", ou seja, levar em conta o contexto em que ele se insere;

$\sqrt{ }$ retratar a realidade com as dimensões presentes na situação, focalizando o objeto (Programa de Intercâmbio na Irlanda) como um todo, evidenciando sua complexidade e a inter-relação dos seus componentes;

$\sqrt{ }$ usar uma variedade de fontes de informação, recorrendo a dados coletados em diferentes momentos, em situações variadas e com distintos informantes.

Quanto aos fins, a presente pesquisa segue as formas exploratória e quantitativa, devido ao pouco conhecimento acumulado e sistematizado sobre o assunto; descritiva, pois compreendeu a obtenção e a exposição dos dados representativos da situação estudada e 
aplicada, na medida em que foi motivada pela possibilidade de equacionar questões concretas e por possuir uma finalidade prática.

Com relação aos meios, realizou-se uma pesquisa documental, na qual foi feita uma revisão dos documentos sobre o assunto, visando fundamentar teoricamente o trabalho, utilizando material publicado em livros, artigos, revistas, internet; utilizados documentos produzidos por órgãos do Governo Irlandês relacionados ao assunto.

\subsection{População de Estudo.}

A população de estudo foi definida a partir do envolvimento dos atores com o Programa de Intercâmbio, de forma a permitir a maior fidedignidade possível das informações e das percepções a respeito do Programa.

Nesse sentido, foi definido o grupo formado pelos estudantes das principais Instituições de Ensino da Língua Inglesa no Distrito Federal: Eagle-Taguatinga, Number OneLago Sul, Wisdom-Lago Sul, Centro Interescolar de Línguas de Brasília-Asa Sul. 


\subsection{Caracterização da população.}

\subsubsection{Estudantes das Instituições da Língua Inglesa:}

150 estudantes de Instituições de ensino da língua inglesa não envolvidas diretamente com programas de intercâmbio. A escolha das instituições de ensino foi feita visando a distribuição de renda em cada setor/bairro, e quantidade de distribuição dos questionários foi efetuada conforme a receptividade e disponibilidade dos estudantes para preenchimento do formulário. Tabela 1- Caracterização da população de estudantes.

\begin{tabular}{|c|c|}
\hline \multicolumn{2}{|c|}{ Instituições pesquisadas } \\
\hline Nome da Instituição & Quantidade Questionário distribuído \\
\hline Eagle - Taguatinga & $\begin{array}{c}30 \\
\text { (retornado preenchido: } 26 \text { ) }\end{array}$ \\
\hline Centro Interescolar de Línguas de Brasília - Asa Sul & $\begin{array}{c}50 \\
\text { (retornado preenchido: } 31 \text { ) }\end{array}$ \\
\hline Number One - Lago Sul & $\begin{array}{c}40 \\
\text { (retornado preenchido: 29) }\end{array}$ \\
\hline Wisdom - Lago Sul & $\begin{array}{c}30 \\
\text { (retornado preenchido: 4) }\end{array}$ \\
\hline
\end{tabular}

Tabela 1 


\subsection{Coleta de Dados.}

A coleta de dados ocorreu, basicamente, em duas etapas e com diferentes finalidades: os dados que visaram fundamentar teoricamente o assunto Intercâmbio foram coletados por meio de levantamento sistemático de livros, artigos em revistas, teses e dissertações, documentos localizados no acervo da Embaixada da Irlanda, da Biblioteca UnB, tendo em vista a contemporaneidade do tema, também recorreu-se à Internet.

Na outra etapa, foi utilizado um instrumento de coleta, para obter dados destinados a identificar perfil dos estudantes de cursos de inglês e o que influência o estudante na escolha do país para intercâmbio.

\subsubsection{Questionário para estudantes de Instituições de Ensino da Língua Inglesa.}

Trata-se de um questionário destinado aos estudantes de Instituiçõos de ensino da língua inglesa, entregue para ser devidamente preenchido e devolvido durante o período de aula. Essas informações referem-se a identificação se desejam ou não fazer algum programa intercâmbio e o que influenciam diante da escolha do país. 


\subsection{Análise dos Dados.}

Os dois instrumentos de coleta de dados, discriminados no item anterior serão analisados em separado, por serem estruturalmente distintos.

A consolidação das informações levantadas no instrumento, analisadas a seguir, consta do capítulo "Resultados e Discussão", na seqüência deste. 


\section{Intercâmbio.}

\subsection{Antecedentes do Programa.}

Ao investigar a origem do uso do termo "intercâmbio", encontramos uma referência à adoção do programa:

De certa forma, a palavra "intercâmbio" acabou por denominar, de forma mais ou menos genérica, os programas de estudo de jovens colegiais. A idéia é que brasileiros estudem nos EUA, assim como americanos estudem no Brasil, por seis meses ou um ano. Hoje, esses programas atingem um número variado de países, sendo a Austrália uma das “descobertas" mais valorizadas pelos nossos jovens. Evidentemente, os Estados Unidos ainda prevalecem como a maior vedete desses programas.

Alguns brasileiros, ao ouvirem a palavra "intercâmbio", pressupõem que, necessariamente, deverão hospedar americanos como contrapartida à hospedagem de seus filhos nos EUA. Embora alguns programas tenham esse tipo de compromisso (do Rotary $C l u b$, por exemplo), esta não é a regra. Além disso, há bolsas de estudo para alguns casos (raros). Como regra geral, certos custos devem ser pagos pela família brasileira.

(Lima,1995,pág.15)

O programa realizado pelo "intercâmbio" pressupõe, tal qual a modalidade das relações culturais entre nações que leva o mesmo nome, conforme o verbete do Dicionário EDIOURO (2000), a troca ou permuta entre os paises. Dessa forma, um "programa intercâmbio" envolve um período no exterior, com residência em casa de família, alojamento na própria escola ou hotel, permitindo a incorporação dos conhecimentos e das experiências vivenciadas em outros países. 
Mac-Dowell, (1998), ao defender a idéia de por que estudar no exterior, delineia as bases do Programa, que veio a ser implementado pelas Agências de Viagens e Centrais de Intercâmbio, e que constitui objeto do presente estudo. De seu texto sobre o assunto, destacam-se as seguintes afirmações, sugestões e observações, que denotam a relevância de um curso de língua no exterior:

O mundo sem dúvida está mudando, e mudando rapidamente. Parte dessa mudança vem do crescimento da econômica, o que é um desafio estimulante para todos nós. As pessoas estão começando a olhar para além de suas fronteiras em busca de uma educação altamente qualificada. O novo paradigma econômico se baseia cada vez mais no conhecimento, na inovação tecnológica e na criatividade.

O valor prático de uma educação internacional é amplamente reconhecido. Nos próximos anos a rede mundial de comunicação, que seja pessoal ou empresarial, será um prêmio para a troca de informações culturais e experiências. Na realidade, o alcance global das empresas exigirá determinadas qualificações de seus executivos.

Em termos de vida pessoal, experimentar outra cultura enriquece o indivíduo de conhecimentos, além de ajudá-lo a compreender melhor o mundo e apreciar mais a sua própria cultura.

(MAC-DOWELL, 1998, pág.7)

Prosseguindo, Mac-Dowell, (1998) alega que profissionalmente uma experiência no exterior, é um fator determinante no mercado competitivo da atualidade. Afirma que "aprender um idioma é extremamente importante, e que aliando isso a cultura e aos contatos pessoais feitos durante um curso agrega inúmeros valores educacionais, não somente para o individuo se incorporar no mercado de trabalho mas, também, para o exercício da cidadania". 


\section{Irlanda.}

\subsection{Características do país.}

1. Geografia e População: Situada ao oeste da Europa à ilha da Irlanda tem uma superfície de aproximadamente 84.500 quilômetros quadrados, possui 450 quilômetros de comprimento e 300 quilômetros de largura. A República da Irlanda (também chamada Irlanda do Sul) possui 26 províncias. A população é de aproximadamente 3.8 milhões de habitantes. Capital: Dublin.

2. Clima: A Irlanda possui um clima suave e temperado, com temperaturas entre $15^{\circ}$ e $20^{\circ} \mathrm{C}$ no verão. A temperatura na primavera e no outono fica em torno de $10^{\circ} \mathrm{C}$ e no inverno entre $5^{\circ} \mathrm{C}$ e $8^{\circ} \mathrm{C}$ e raramente neva. Pode chover em qualquer época do ano, mas sempre por curtos períodos.

3. Idioma: O irlandês (gaélico) e o inglês são as duas línguas oficiais da Republica da Irlanda, sendo que todos falam o inglês.

4. Moeda: O Euro é a moeda corrente na República da Irlanda.

5. Atrações culturais: Pontos de encontro com entretenimento musical, museus, castelos e seus banquetes medievais, galerias de arte, teatros, catedrais, Abadias medievais, clubes e restaurantes.

Figura 1:

Dublin

Fonte: Guia Belta

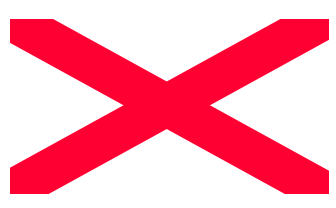


Dizem que a Irlanda é uma terra de músicos, escritores e sonhadores. Talvez seja por isso que ela tem dado ao mundo brilhantes romancistas e poetas. No Museu dos Escritores, na Frederick Street, também em Dublin, encontram-se edições originais, manuscritos, cartas e objetos de figuras como Jonathan Swift, autor de As viagens de Gulliver, James Joyce (Ulisses), George Shaw (Pigmalião - My Fair Lady, na versão musical), Oscar Wilde (Retrato de Dorian Gray), e W. B. Yeats, autor de poemas considerados os mais perfeitos da língua inglesa.

De toda a comunidade européia, é o país com a mais alta proporção de jovens: de $35 \%$ a $40 \%$. Não é à toa que a Irlanda exporta música jovem, como a produzida por U2, Ash, Sinead OConnor, Van Morrison ou Thin Lizzy. A doce canção de Enya também é produto irlandês.

Macris, 2003.

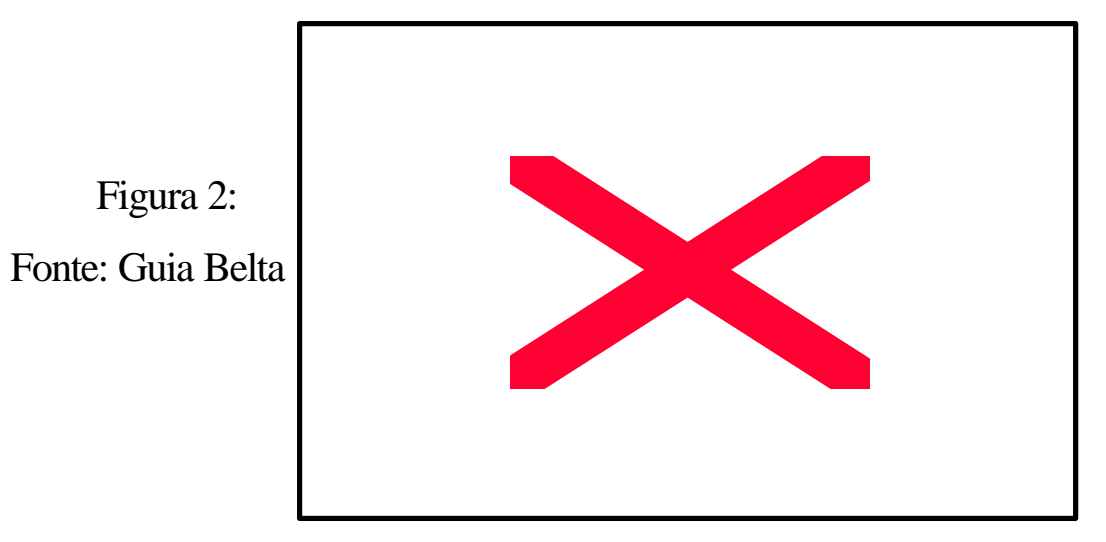

6. Lazer: Paisagens encantadoras (montanhas, colinas, vales, lagos, belas praias, parques florestais, magníficas ruínas), famosas destilarias de uísque, esportes (aquáticos, caça, pesca, golfe, rapel e outros). O nterior da Irlanda é ótimo para a prática do ciclismo, montanhismo e caminhadas. Há clubes que oferecem equipamentos e formação para atividades como canoagem, wind-surf, golfe, hipismo e montaria. Assistir a uma corrida de cachorros também pode ser divertido. As pistas irlandesas de greyhound, em que são realizadas corridas de cães da raça galgo, são de padrão internacional.

7. Sistema Educacional: O Departamento de Educação e Ciência administra, supervisiona e financia os serviços de educação do primeiro, segundo e terceiro grau e opera o sistema de inspeção de Estado nas escolas.

O sistema educacional compreende 4 modalidades: 
Educação primária - idade de 6 a 15 anos, caracterizado como $1^{\circ}$ grau, ensino fundamental centralizado nas necessidades e interesses das crianças.

Educação pós-primária - $2^{\circ}$ grau, ensino vocacional.

Educação complementar - Em adição para os cursos proporcionados no $3^{\circ}$ grau, com mais variedades para o ensino vocacional e cursos de treinamento para os estudantes de completaram o ensino secundário.

Educação terceiro nível $-3^{\circ}$ grau, compreende o setor de faculdades e universidades.

A reportagem abaixo afirma o investimento e dedicação para o desenvolvimento educacional no país:

"Educação muda o rumo da Irlanda - O embaixador do Brasil na Irlanda, Armando Frazão, fez nesta terça-feira um relato ao ministro da Educação, Cristovam Buarque, de como a Irlanda, em 30 anos, de 1973 a 2003, deixou de ser, pela via da educação, a mais pobre nação da Europa para se tornar um país europeu normal. Foram três décadas de investimentos a fundo perdido, disse o embaixador".

A decisão tomada em 1973, na véspera da Irlanda ingressar na Comunidade Econômica Européia, explicou Armando Frazão, foi que, independente de qual partido político estivesse no poder, as prioridades do país seriam a saúde universal, a educação gratuita para todos até o quarto nível, e a ciência e tecnologia. O compromisso, mantido durante 30 anos, levou a Irlanda a ter hoje índices invejáveis em mão-de-obra qualificada, que desperta o interesse de outros países.

Com uma população de 3,6 milhões de habitantes, seus profissionais na faixa etária de 27 a 32 anos representam um dos maiores índices mundiais de mestres e $\mathrm{PhDs}$ por habitante. Esse avanço, explicou o embaixador Frazão, é conseqüência direta do investimento em educação. Mesmo tendo conseguido essa marca, a Irlanda não conseguiu erradicar o analfabetismo. O país tem 500 mil analfabetos entre 55 a 70 anos. No documento que entregou ao ministro Cristovam, o embaixador informa que o governo irlandês fez diversas tentativas para convencer os adultos da importância da alfabetização, mas encontrou resistências: a vergonha de admitir o analfabetismo, embora esses adultos sejam os pais das gerações com alto grau de escolaridade. (MEC)".

IG Educação, 2003 
8. Forma de Governo: Parlamentarismo - Democrático.

9. Principais atividades: Alta tecnologia, pecuária, indústrias farmacêuticas.

10. Principais produtos: Laticínios, carne, software, químicos/farmacêuticos. 
Figura 3: Mapa da Irlanda, Fonte: Bord Fáilte - Irish Tourist Board 


\section{Programa de Intercâmbio na Irlanda para Estudantes Brasileiros.}

\subsection{Caracterização do Programa.}

Estabelecido desde 1960, Ireland's English as a Foreign Language (EFL) - Inglês na Irlanda para Estrangeiros, desenvolveu uma indústria de negócios significante, contribuindo entre $£ 265$ e $£ 275$ milhões para economia em 1999.

A indústria $E F L$ proporciona aprendizagem da língua inglesa para não-nativos, abrangendo estudantes Junior idade de 10 a 17 anos e para adultos com a idade acima de 18 anos.

Esse item trata da caracterização do contexto e dos atores, no Brasil (estudantes) e na Irlanda (Instituições de Ensino). Abordam-se os aspectos que influenciam o Programa de Intercâmbio naquele país. Criando as condições para a sua implementação, entre as quais diretrizes dos dois países que, no caso deste estudo, situam-se no âmbito da cooperação educacional, entre o Brasil e a Irlanda, além da articulação entre os atores e da formatação das parcerias a ser estabelecidas entre eles, para fins da cooperação acordada.

O Programa de Intercâmbio de Estudantes, do qual trata este estudo, visa a cooperação dos principais órgãos responsáveis pelo desenvolvimento do programa Irland's English as a Foreign Language-EFL (idioma inglês para estudantes estrangeiros na Irlanda). Os quais são:

- MEI RELSA Ireland - uma reconhecida associação irlandesa fornecedora do EFL .

- Advisory Council for English Language Schools (ACELS) - o propósito deste Conselho é garantir uma dedicação na qualidade da educação exemplar padronizada no futuro. 
- Bord Fáilte - Departamento governamental responsável pelo marketing e divulgação da Irlanda como destino pelos estrangeiros para aprendizagem da língua inglesa.

\subsection{Histórico dos Parceiros no Mercado de Intercâmbio para Irlanda.}

\subsubsection{Conselho para Escolas da Língua Inglesa (ACELS).}

O ACELS foi fundado em 1972 pelo Governo Irlandês sob o patrocínio do Departamento de Educação e Ciência, o qual reconheceu que a falta de uma apropriada educação EFL estava prejudicando o crescimento do programa de intercâmbio. Como resultado, eles estabeleceram um novo Conselho "The Advisory Council for English Language Schools" -Conselho para as Escolas da Língua Inglesa. Este Conselho foi fundado pelo Ministério da Educação para apoiar um Departamento responsável pela legalização das escolas do EFL. O Conselho de Inspetores examina as escolas antes de aprovar o funcionamento, o mesmo autoriza ou orienta mudanças recomendadas caso haja deficiência em alguma área. O Conselho é composto de representantes do MEI RELSA, Departamento de Relações Exteriores, Departamento da Justiça, Organização de Turismo Regional, Bord Fáilte, Membros da Indústria autorizados pelo Departamento de Educação e Ciência. Os quais buscam como objetivo garantir um programa dedicado a qualidade na excelência no futuro. $A C E L S$, entretanto, atua como responsável pelo aumento do mercado de escolas qualificadas $E F L$ irlandesa. Eles têm desenvolvido escolas $E F L$ irlandesas qualificadas e conseqüientemente mostrando um programa de credibilidade no mercado competitivo. 


\subsubsection{MEI RELSA Ireland - Associação irlandesa fornecedora do EFL .}

MEI, foi fundado em 1993, como grupo de marketing co-operativo para escolas particulares da língua inglesa. Tendo como objetivo promover os interesses dos membros das escolas no exterior, desenvolvendo e emergindo o mercado.

MEI RELSA foi formada em Janeiro 2000 como resultado de uma união entre duas organizações, Associação das Escolhas da Língua Inglesa (RELSA) e Marketing do Inglês na Irlanda $(M E I)$.

Desde sua formação em 1987, RELSA representou os interesses em disseminar o reconhecimento das escolas na Irlanda. Inicialmente focalizaram na qualidade acadêmica, o bem-estar do estudante e promover excelência na indústria $E F L$ na Irlanda. O desempenho da RELSA foi notável na habilidade de capacitar os membros das escolas, fixar certificados de treinamento dos professores, passando por treinamento intensivo para se tornarem professores de cursos EFL.

Após a fusão a organização é chamada MEI RELSA Ireland e é composta por 60 membros operando em 125 centros no país e representa o Conselho The Advisory Council for English Language Schools e The International Education Board of Ireland.

Escolas MEI RELSA Ireland são reconhecidas pelo Departamento de Educação e Ciência como escolas da língua inglesa que capacita professores através de cursos especializados para o ensinamento da língua Inglesa para estrangeiros. A Associação interage para melhorar a qualificação de seus membros e como co-operadora no marketing para estabelecimento e desenvolvimento do mercado. 


\subsubsection{Bord Fáilte.}

MEI RELSA Ireland desenvolveu juntamente com o Bord Fáilte um relacionamento de marketing para mercado no exterior. Bord Fáilte executa o papel de desenvolvimento do mercado através de seus representantes que, freqüentemente estão viajando para divulgar o mercado no exterior juntamente com MEI RELSA Ireland como EFL para destino.

Bord Fáilte tem cooperado na divulgação e conscientização da Irlanda no exterior. Como resultado o mercado Irish EFL tem se beneficiado no aumento da demanda.

\subsection{Potência do $E F L$ no Mercado de Intercâmbio.}

Segundo as análises do Enterprise Ireland - Órgão Governamental responsável pela divulgação do turismo na Irlanda. As qualificações daquele país no mercado de intercâmbio podem ser resumidas em:

- Imagem da Irlanda no exterior como um país: pequeno, seguro e de população amigável.

- A qualidade de acolhimento irlandês.

As escolas de inglês irlandesas oferecem diferentes opções de hospedagem aos seus estudantes. Desde luxuosos castelos e modernos hotéis até guesthouses-casa de família na cidadade e farmhouses-casa de família em fazenda, que oferecem um serviço pessoal e proporcionam a convivência com uma típica família irlandesa. Existem albergues para jovens e famílias, campings e áreas reservadas para trailers.

Macris, 2003. 
- A qualidade do produto EFL na Irlanda.

Segundo revista MEI-RELSA (2003, pág. 4), "há muitas escolas com método e padrão de ensino de altíssima qualidade, capazes de atender às necessidades de estudantes e pessoas de negócios".

No Relatório Nacional Programa Internacional de Avaliação de Alunos - PISA 2000 (2001, pág. 85) afirma que "a Irlanda faz parte de um grupo de países de primeira linha. São países relativamente pequenos, altamente homogêneos e teimosamente dedicados à educação".

- Crescimento da economia influenciando aumento no investimento do mercado estrangeiro.

- Família anfitriã estruturada.

Eles podem falar a língua dos ingleses, mas o jeito de ser é muito mais ligado ao dos brasileiros do que ao dos vizinhos britânicos.

Macris, 2003.

- Sucesso da Associação MEI RELSA e do Conselho ACELS está garantindo qualidade nos serviços relacionados ao intercâmbio estudantil. 


\subsubsection{EFL no Mercado de Intercâmbio.}

A essência do produto EFL tem mudado significantemente nos últimos anos. Cinco anos atrás os clientes estavam interessados principalmente no curso de língua. Enquanto a qualidade dos cursos e de ensinamento é ainda de suprema importância, os fornecedores desses serviços reconhecem a importância de oferecer aos clientes produtos mais sofisticados e serviços complementares que proporcione valor adicional. Ampliando a demanda do inglês para propósitos específicos e cursos de inglês para negócios.

\subsubsection{Processo utilizado pelos estudantes que escolhem como destino o $E F L$ na Irlanda.}

De acordo com a pesquisa da Enterprise Ireland 2001, atualmente, os estudantes seguem os seguintes passos na escolha do curso específico:

a) efetuam pesquisa na internet para adquirirem conhecimentos sobre a visita na Irlanda e escolha de um curso conforme sua preferência.

b) contatam o agente internacional mais próximo para finalização dos requerimentos necessários para inscrição.

A tendência para inscrição dos estudantes com destino $E F L$, é através de agentes internacionais e/ou pesquisa na internet. Em 1999, foi constatado que $60 \%$ do EFL irlandês vieram de agentes internacionais. Confirmou-se que os estudantes utilizam a internet para pesquisa, mas a maioria contata agentes internacionais para preenchimento de requerimentos necessários na inscrição e pagamento do curso. Entretanto, constatou-se que os estudantes estão começando a utilizar a internet para efetuar sua inscrição no curso. 


\subsubsection{Origem dos principais clientes/estudantes que escolhem como destino o EFL da Irlanda.}

Conforme constatado na pesquisa da Enterprise Ireland 2001, os países da Europa Continental representam grande parte a proporção de estudantes EFL viajando para Irlanda. Exemplo, o caso da Espanha e Itália com $79 \%$ na demanda, compreendendo $40 \%$ de estudantes espanhóis em 1999. A mesma porcentagem é representada pelos estudantes italianos aproximando de $40 \%$ no mesmo ano. A Irlanda alcança também o mercado em dois paises no centro do oeste Europeu; a Alemanha e França.

Em termos de desenvolvimento no mercado, a Europa oriental apresenta uma nova oportunidade para crescimento. Estudantes vindo da Polônia, Rússia e Hungria têm aumentado nos últimos 18 meses com a conscientização da Irlanda como pais de destino para aprimoramento e aprendizagem da língua inglesa.

Finalizando a pesquisa Enterprise Ireland 2001, afirma que, a América do Sul oferece significante potencial de crescimento no futuro. Considerando que grande parte de estudantes dessas regiões possuem baixo conhecimento sobre o que oferece o mercado de intercâmbio da Irlanda . 


\section{Países competidores no Mercado de Intercâmbio.}

O mercado de concorrentes com a Irlanda como destino para EFL abrange a Inglaterra, e países como Austrália e Nova Zelândia. Segundo pesquisa da Enterprise IrelandStrategic analysis of Ireland's English as a Foreign Language industry,2001. Uma vantagem que a Irlanda desfrutou sobre a Inglaterra, e que nos últimos dois anos, o valor da moeda irlandesa punt esta menor comparando com o valor da moeda inglesa o sterling. Isto tem proporcionado a Irlanda uma significante vantagem de preços sobre um dos maiores competidores internacional. Como efeito alertando agências e estudantes da existência da Irlanda como uma viável alternativa para destino $E F L$.

\subsection{Mercado Competidor da Inglaterra.}

A Inglaterra permanece como principal competidor da Irlanda no EFL. A estrutura do mercado na Inglaterra é muito diferente do mercado Irlandês. A principal diferença é o papel ativo do governo na promoção do programa de intercâmbio.

De acordo com o setor inspeção de passageiro internacional da Inglaterra, a estimativa foi de 633.000 estudantes viajando para Inglaterra para o programa EFL em 1999, abaixo de 640.000 em 1998 e 643.000 em 1997. Entre 1998 e 1999, aumentou de 156.000 para 200.000 o número de estudantes matriculados nas escolas irlandesas $E F L$, estimativa de $20 \%$ de aumento. 


\subsubsection{Organização da Indústria.}

Em termos de estrutura, há atualmente 211 reconhecidas escolas particulares da língua inglesa na Inglaterra. Um grande número de universidades e escolas públicas adotaram o programa EFL. Há inúmeros operadores de turismo não tradicionais, que recentemente começaram a diversificar adotando a indústria EFL. Há duas principais associações no programa de intercâmbio: Associação reconhecedora das escolas da língua inglesa - ARELS e Associação Britânica Estadual de Ensino da Língua Inglesa - BASELT.

ARELS é uma associação das escolas particulares e a BASELT é uma associação das faculdades e universidades no setor estadual de educação britânica, com o objetivo de melhorar o padrão do inglês para estrangeiros entre faculdades e universidades.

Apesar dessas organizações atuarem independentemente, os interesses de ambas são representados no exterior através do British Council, que funciona como uma Instituição de ensino da língua inglesa no exterior, o qual influência fortemente no marketing de divulgação no exterior.

Vantagens do mercado na Inglaterra:

- percepção mundial como centro do mundo para falar inglês

- tarifa inferior para acesso de avião ou trem entre os paises europeus

- atração pelo inglês de "Oxford"

- variedade na escolha do produto

Desvantagens do mercado na Inglaterra:

- valor muito alto da moeda sterling 


\subsection{Mercado Competidor da Nova Zelândia .}

Segundo afirma Valquiria MacDowell, o país é famoso pela excelente qualidade de vida. A Nova Zelândia é um dos lugares mais seguros do mundo. A polícia não anda armada e usa cães nas batidas policiais. O custo de vida é mais barato devido à troca da moeda. É parecido com a Austrália, sendo assim mais baixo do que dos Estados Unidos, Canadá e Inglaterra. Conseqüentemente, o estudo lá não é caro. As escolas são públicas, mas com computadores nas salas de aula, turmas de no máximo 25 alunos e horário integral das oito da manhã até às três da tarde. O sotaque dos "kiwis", como são conhecidos os nativos do país, é bem parecido com o inglês britânico. Isso tudo é um grande atrativo para os intercambistas.

O ano letivo é igual ao do Brasil. A diferença é que são dez semanas de aula e duas de férias. "A vantagem dos programas de intercâmbio na Nova Zelândia é que os estudantes sempre são encaixados em famílias que têm o mesmo interesse que eles", conta, diretora da Improvement, empresa que tem mandado muitos jovens para aquele país. Ótima oportunidade para conhecer cada cantinho desse país que reserva maravilhas para os jovens aventureiros.Quem sabe bem disso é Lais Vangazebrouck, de 16 anos, que acaba de voltar da Nova Zelândia depois de um ano de intercâmbio. A estudante foi para Auckland, ficou na casa de uma família e fez high school. Não há dúvida de que a experiência foi inesquecível. "Valeu porque você vê como as pessoas vivem lá. Não há sofisticação. Volto no ano que vem". Mas maior empolgação ainda Lais tem ao contar sobre os esportes radicais que praticou. "Fiz páraquedismo. Junto com mais um grupo de intercambistas, Lais também fez rafting numa corredeira. 


\section{Resultados e Discussão.}

Como resultado da pesquisa no capitulo " 5 " os seguintes resultados merecem destaque:

1) Dos 53 estudantes do sexo feminino 22 disseram que querem fazer intercâmbio, ou seja, 41,5\% do total, dos 35 estudantes do sexo masculino apenas 10 disseram que desejam fazer intercambio, ou seja, $28,6 \%$ do total.

Podemos concluir que o público mais interessado em fazer intercâmbio é feminino.

2) Dos 53 estudantes do sexo feminino 24 disseram que talvez querem fazer intercâmbio, ou seja, 45,3\% do total, dos 35 estudantes do sexo masculino 19 disseram que talvez desejam fazer intercâmbio, ou seja, 54,3\% do total.

Podemos concluir que ambos os sexos igualmente não se definiram.

3) Dos 53 estudantes sexo feminino 6 disseram que não querem fazer intercâmbio, ou seja, 11,3\% do total, dos 35 estudantes sexo masculino 6 disseram que não querem fazer intercâmbio, ou seja, $17,1 \%$ do total.

Podemos concluir que $\mathrm{n}$ ão há diferença significanteentre os sexos que não querem fazer intercâmbio.

4) Dos 17 estudantes que estudam em escolas ou faculdades públicas, 5 desejam fazer intercâmbio, correspondente a 29,4\% do total. Dos 67 estudantes que estudam em escolas ou faculdades privadas 26 desejam fazer intercâmbio, ou seja 38,8\% do total.

Pode se concluir que estudantes em escolas/faculdades particulares têm um pouco mais de interesse em fazer intercâmbio do que os estudantes das escolas/faculdades públicas. 
Dos estudantes de escolas públicas $17 \%$ não querem fazer intercâmbio e das privadas $13 \%$, pouca diferença.

5) Dos 45 estudantes que moram em cidades satélites 19 desejam fazer intercâmbio, ou seja, 42,2\%; enquanto dos 32 alunos moradores dos lagos sul e norte apenas 8 desejam realizar intercâmbio, ou seja $25 \%$ do total.

Pode-se concluir que existe um maior público interessado em fazer intercâmbio nas cidades satélites do que nos lagos sul e norte. Isto pode significar também que a renda familiar não impede o desejo de fazer intercâmbio, ou talvez até estimula: menor a renda familiar maior o desejo de realizar intercâmbio.

Verificamos este item com cruzamento de dados da renda familiar e o desejo de fazer intercâmbio:

- 1 a 3 salários mínimos $\quad 50 \%$ desejam fazer intercâmbio

- 4 a 6 salários $\quad 20 \%$ desejam fazer intercâmbio

- 7 a 11 salários $\quad 37,5 \%$ desejam fazer intercâmbio

- acima de 11 salários 34,8\% desejam fazer intercâmbio.

Não pode se tirar conclusões decisivas sobre a hipótese levantada da relação entre renda e desejo para intercâmbio.

6) Para os estudantes do sexo feminino a escolha do país é definida por:

$\begin{array}{ll}\text { Cultura } & 47 \% \\ \text { Qualidade do ensino } & 33,9 \% \\ \text { Lazer } & 22,6 \% \\ \text { Localização } & 16,9 \% \\ \text { Preço } & 1,8 \%\end{array}$


O interessante é que o preço quase não influência na escolha.

- Para os estudantes do sexo masculino a escolha do país é definida por:

$\begin{array}{ll}\text { Cultura } & 48,5 \% \\ \text { Lazer } & 42,8 \% \\ \text { Qualidade de ensino } & 28,6 \% \\ \text { Localização } & 22,8 \% \\ \text { Preço } & 8,5 \%\end{array}$

O interessante é que o público masculino dão mais valor ao lazer do que o público feminino: $42,8 \%$ verso $22,6 \%$, e menos valor a qualidade do ensino.

Os paises mais escolhidos para intercâmbio foram 24\% Estados Unidos e 16\% Inglaterra. 


\section{Conclusão.}

Conforme resultado dos 90 questionários preenchidos pelos estudantes da língua inglesa, o público mais interessado em fazer intercâmbio é do sexo feminino e mora nas cidades satélites, e a Irlanda quase não aparece como opção de interesse enquanto possui toda característica necessária para decisão de escolha.

Constatou-se através da pesquisa literária que a Irlanda dispõe de potencial para ser competitivo no mercado de intercâmbio, pois harmoniza cultura, lazer, qualidade de ensino entre outros aspectos relevantes mencionados nas características do pais. Entretanto, somente $1 \%$ dos estudantes escolheu a Irlanda como pais de destino para o intercâmbio.

Participo ainda que em relação ao nível de conhecimento dos estudantes sobre a Irlanda a maioria das respostas foi $48 \%$ localização do país e $40 \%$ da música em especial a banda U2. Demonstrando que o país é pouco divulgado, principalmente em relação a sua cultura, lazer e qualidade de ensino considerando que foi subseqüentemente os principais aspectos para a escolha do país para intercâmbio. É importante observar que a Irlanda apenas há 2 anos mantém uma representação diplomática no Brasil, e que para aumentar a demanda de intercâmbio de estudantes brasilienses para aprendizagem da língua inglesa naquele país dependerá da disponibilidade de divulgação da Irlanda no Brasil. 


\section{Referências Bibliográficas.}

Publicado pelo Departamento de Relações Exteriores Irlandês. Facts about Ireland, Dublin, 2001.

Publicado pelo Departamento de Relações Exteriores Irlandês. Ireland in Brief, Dublin,2001.

Publicado pelo Departamento de Turismo da Irlanda. Ireland-Revista de Férias e Guia de Viagem, Dublin, 2002.

Publicado pelo Departamento de Educação Irlandês, Ireland-The quality location for learning English, Dublin, 2003.

Publicado pelo Governo Irlandês, Enterprise Ireland-Strategic analysis of Ireland's English as a Foreign Language industry, Dublin,2001.

Publicado pelo Departamento de Educação Internacional Irlandês, Education Ireland, Dublin, 2002.

Mac-Dowell, Valquiria. Sem Fronteiras: guia prático para estudar no exterior do $1^{\circ}$ grau à pósgraduação. Rio de Janeiro:Campus, 1998.

Lima, Afonso. Como estudar nos EUA/Afonso Lima. Rio de Janeiro:Record, 1995.

Vallandro, Lino. Dicionário SpeakUp: inglês-português, português-inglês. São Paulo: Globo, 1997.

Ximenes, Sérgio. Minidicionário da Língua Portuguesa, São Paulo: Ediouro, 2000. 
Sampaio, Ana. O Programa de Graduação Sanduíche na França para a formação de recursos Humanos em Engenharia: Uma Experiência de Parceria entre o Estado e a Indústria. Dissertação de Mestrado. Faculdade de Educação: Universidade de Brasília,2002. 98pág.

Educação, Departamento de Educação Internacional. Irlanda, julho,2003. Seção Educação para estrangeiros. Disponível na Internet em : 〈http://www.educationireland.ie $>$, acesso em 25 julho 2003.

Turístico, Guia Belta, Rio de Janeiro, junho, 2003. Seção visite Dublin . Disponível na Internet em : <http://www.guiabelta.com.br/NoticiaDetail.asp?codNoticia=3206>, acesso em 10 junho 2003.

Turismo, Departamento de Esporte, Turismo e Recreação. Irlanda, agosto,2003. Seção Turismo. Disponível na Internet em : 〈http://www.irlgov.ie/tourism-sport〉, acesso em 03 agosto 2003 .

Comercial, Gestão e Recursos Humanos Editora, São Paulo, janeiro,2004. Seção Exigência do mundo globalizado. Disponível na Internet em :

http://www.gestaoerh.com.br/visitante/artigos/cap_gp07.php, acesso em 16 janeiro 2004.

Turismo, Improvement Intercâmbios, Curitiba, janeiro, 2004. Seção Aventuras Radicais. Disponível na Internet em: http://revistaturismo.cidadeinternet.com.br, acesso em 16 janeiro 2004. 
APÊNDICE

Questionário: 
Prezado estudante,

Dirijo-me a você, na condição de aluna do curso Pós-Graduação em Gestão da Hospitalidade,UnB, para pedir sua colaboração no preenchimento do formulário que se segue, construído especialmente para a coleta de dados sobre o Programa de Intercâmbio de Estudantes Brasileiros para Aprendizagem da Língua Inglesa na Irlanda.

Procurei elaborar um instrumento simples e objetivo que pudesse identificar o que influência o estudante na escolha do país como destino para intercâmbio.

Caso você possa contribuir para esse trabalho, peço que observe o seguinte:

- O campo 1 deve ser totalmente preenchido, não sendo necessário colocar seu nome;

- No campo 2 correspondente a sua opção de resposta, assinale tantos itens quanto necessários.

- O campo 3 refere-se, mais especificamente, sobre o nível de conhecimento da Irlanda, portanto, informe somente o que você sabe/conhece sobre o país.

- Os dados coletados e tratados serão utilizados para fins acadêmicos e de forma impessoal;

- Os formulários deve ser preenchidos de forma legível, à mão e podem ser devolvidos diretamente na secretária da instituição, até o dia 6 de novembro de 2003.

Espero poder contar com sua contribuição e agradeço, antecipadamente, a atenção que você dedicar a esse pedido. Peço que, em caso de dúvidas, entre em contato comigo (tel. 248-8800 / 9614-5237) para esclarecimentos sobre o assunto.

Um abraço da

Alice Madruga

Brasília, 28 de outubro de 2003. 
Campo 1: dados de identificação pessoal:

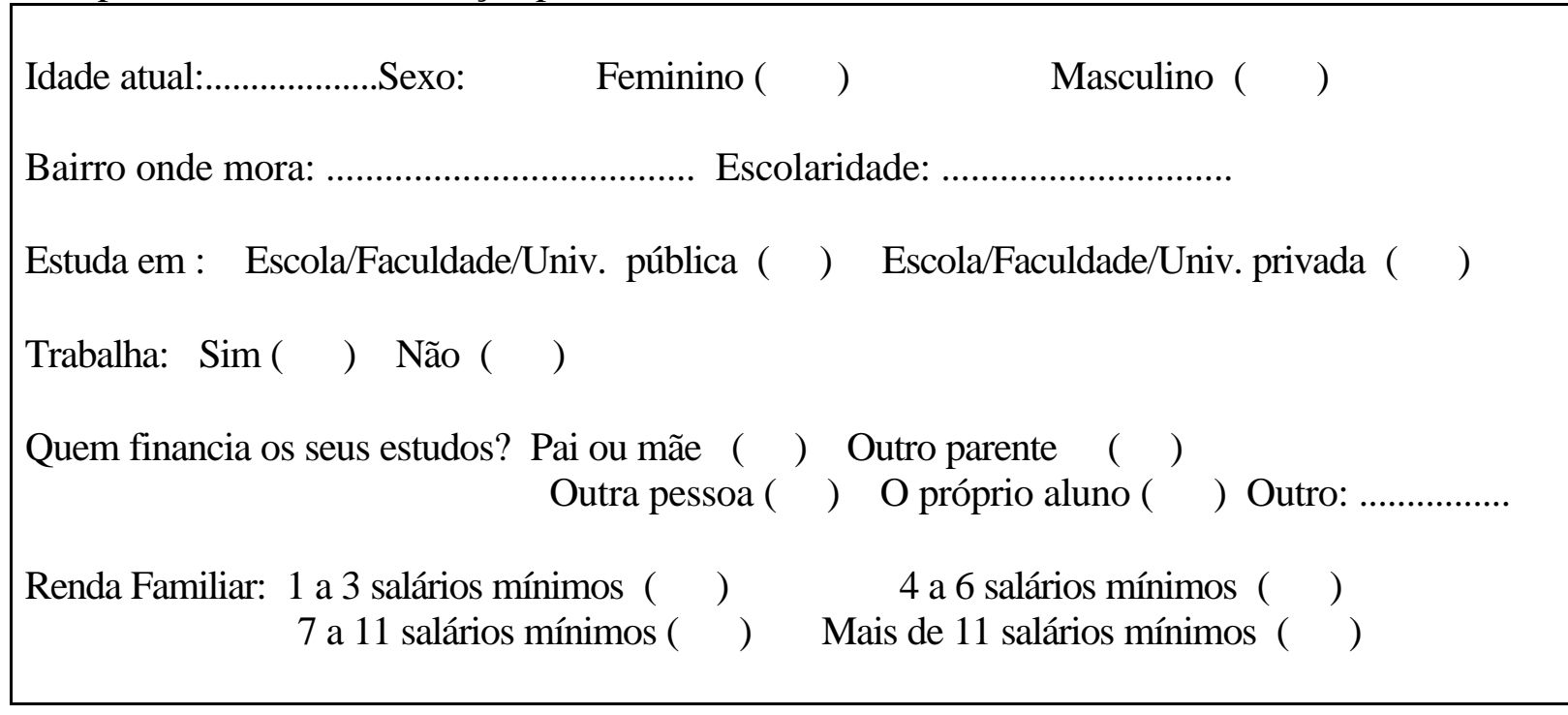

Campo 2:

Você pretende fazer intercâmbio?

Não ( ) Sim ( ) Talvez ( )

(Sim) ou (Talvez) Em que país:

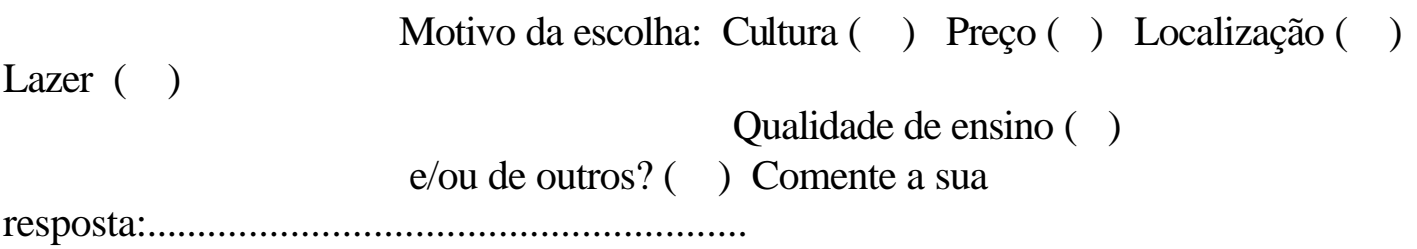

(Não) Sem mais perguntas.

\section{Campo 3:}

O que você sabe/conhece sobre o país da República da Irlanda?

1. Cultura:

2. Música:

3. Lazer:.

4. Literatura:

5. Esportes:

6. Localização:.

7. Outros:... 